\title{
Червенко А.Ю.
}

\section{Прогиб балочной фермы с треугольной решеткой под действием равномерной нагрузки по нижнему поясу}

\author{
Chervenko A.Yu. \\ The deflection of a girder with a triangular lattice under \\ the action of uniform load on the bottom belt
}

Ферма опирается на подвижную и неподвижную опору. Стержни соединены шарнирно. Методами компьютерной математики Maple получено точное выражение для прогиба плоской статически определимой упругой фермы. Использован метод индукции и операторы rgf_findrecur u rsolve

Ключевые слова: ферма, прогиб, индукция,Maple

\section{Червенко Антон Юрьевич}

Студент

Национальный исследовательский университет «МЭИ»

2. Москва, ул. Красноказарменная, 14
The truss relies on movable and fixed support. The rods are connected pivotally. By the methods of computer mathematics Maple an exact expression for the deflection of statically determinate elastic flat truss is obtained. Used induction method and operators rgf_findrecur and rsolve

Key words: truss, deflection, induction, Maple

Chervenko Anton Yurievich

Student

National research university "MPEI"

Moscow, Krasnokazarmennaya st., 14

Аналитическое выражение зависимости прогиба статически определимой фермы с параллельными поясами от числа панелей имеет как теоретическое, так и практическое значение. Получить эту зависимость в виде компактной и удобной в работе формулы можно методом индукции с использованием системы Maple [1]. Ранее этот подход был использован для плоских [2-11] и пространственных ферм [12-14], в задаче о вантовой системе [15] и при анализе деформаций свайного фундамента [16]. Метод применялся и в задаче о жесткости гироскопической подвески [17], при построении линий влияния в плоских фермах [18-19] и в ферме с учетом ползучести материала [20-22].

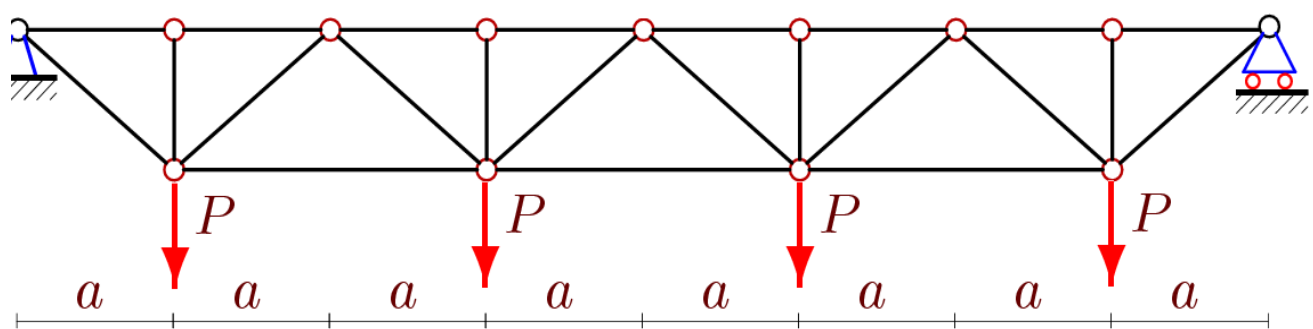

Рис. 1. Ферма с четырьмя панелями (n=4) 
Будем оценивать прогиб фермы (рис. 1) по вертикальному смещению среднего узла верхнего пояса. Используя формулу Максвелла - Мора, приложим единичную вертикальную силу к этой точке и найдем усилия в стержнях $s_{i}, i=1, \ldots, m$, где для фермы с $n$ панелями $m=6 n-1$. Усилия от действующей нагрузки обозначим $S_{i}$. Все усилия в символьной форме находим по программе, написанной на языке Maple [1]. По формуле $\Delta=\sum_{i=1}^{m} \frac{S_{i} s_{i} l_{i}}{E F}$, где $E F$ - жесткости стержней, $l_{i}$ - длины стержней, находим ряд решений для ферм с различным числом панелей. Итоговые формулы оказываются подобными. Коэффициенты в них выстраиваются в последовательности, общие члены которых можно найти, пользуясь операторами rgf_findrecur и rsolve системы Maple. Соответствующий фрагмент программы имеет вид:

$>$ with (genfunc):

$>S:=1,2,5,8,13,18,25,32: \mathrm{N}:=\operatorname{nops}([\mathrm{S}]) / 2$;

$>Z:=r g f$ findrecur $(N,[S], t, n)$;

$>Z Z$ :=simplify (rsolve $(\{z, \operatorname{seq}(t(i)=S[i], i=1 \ldots N)\}, t))$;

В результате получаем искомую формулу $E F \Delta=P\left(A_{n} a^{3}+B_{n} c^{3}\right) /\left(2 b^{2}\right)$, где $A_{n}=\left(10 n^{4}+8 n^{2}+3(-1)^{(n+1)}+3\right) / 24, B_{n}=\left(2 n^{2}-(-1)^{n}+1\right) / 4, c=\sqrt{a^{2}+b^{2}}$.

Зависимость относительного прогиба $\tilde{\Delta}=\Delta E F / P$ от числа панелей отображена кривыми на рисунке 2 (размеры в метрах).

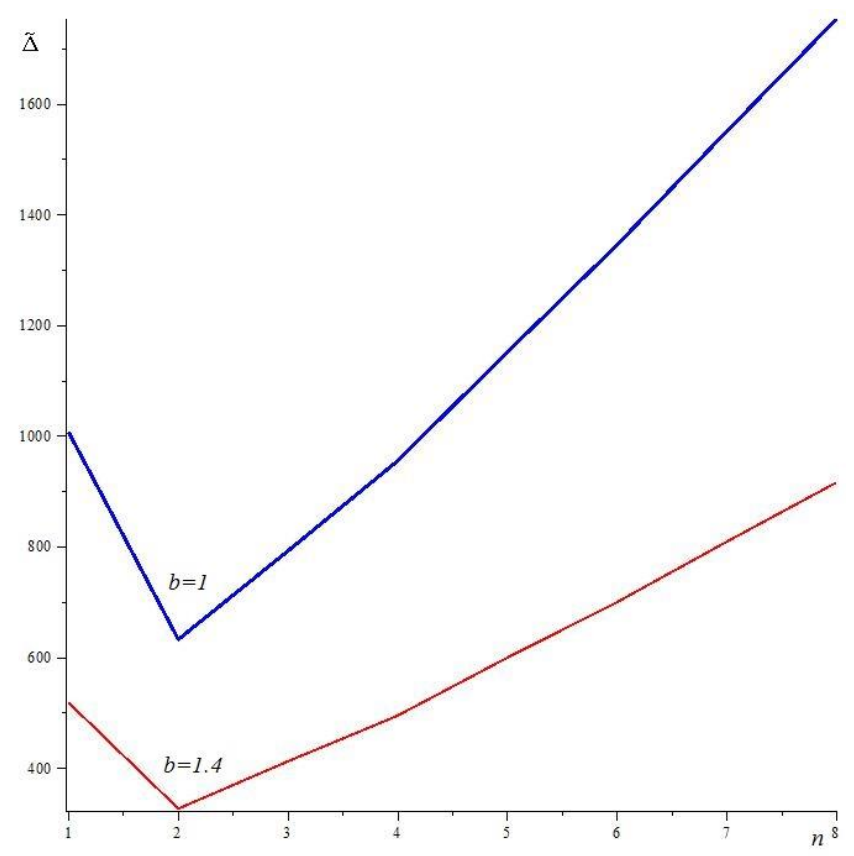

Puс. 2. Прогиб фермы при $L=a n=10 \mathrm{M}$

\section{Список используемых источников:}

1. Кирсанов M.H. Maple и Maplet. Решения задач механики. СПб.: Изд-во Лань, 2012. 512 с.

2. Андросова Д.И. О зависимости прогиба плоской балочной фермы с треугольной решеткой от числа панелей // Вестник научных конференций. 2015. № 2-2(2). C. 14-15. 
3. Кирсанов М.Н. Математическая модель балочной фермы с элементами упрочнения // Инженерностроительный журнал. 2015. №4(56). С. 38-44.

4. Вальтер А. М. Прогиб плоской балочной статически определимой фермы с треугольной решеткой// Вопросы образования и науки: теоретический и методический аспекты. Ч. 1. Тамбов, 2015. С. 53-54.

5. Кирсанов М.Н. Анализ прогиба решетчатой балочной фермы распорного типа // Инженерностроительный журнал. 2015. №5(57). С. 58-65.

6. Кирсанов М.Н. Аналитическое исследование деформаций плоской фермы арочного типа // Вестник государственного университета морского и речного флота им. адмирала С. О. Макарова 2015.

№ 3 (31). C. 42-48.

7. Кирсанов М.Н. Расчет жесткости стержневой решетки // Вестник машиностроения. 2015. № 8.

C. 49-51.

8. Кирсанов М.Н. Аналитический расчет решетчатой фермы // Моделирование и механика конструкций. 2015. № 2 (2). С. 5.

9. Кирсанов М.Н. Точные формулы для расчета прогиба и усилий в стержнях типовой фермы «Молодечно» с произвольным числом панелей // Инженерно-строительный журнал. 2016. №1(61). C. 33-41.

10. Кирсанов М.Н. Формулы для расчета плоской балочной фермы с произвольным числом панелей // Строительная механика и конструкции. 2016. №1. С. 19-24.

11. Кирсанов М.Н. Аналитический расчет регулярной балочной фермы с произвольным числом панелей со сложной решеткой // Строительная механика и расчет сооружений. 2016. № 3. C. 16-19.

12. Кирсанов М.Н. Особенности аналитического расчета пространственных стержневых систем // Строительная механика и расчет сооружений. 2011. №5. С. 11-15.

13. Кирсанов М.Н. Аналитический расчет и оптимизация пространственной балочной фермы // Вестник МЭИ. 2012. № 5. С. 5-8.

14. Кирсанов М.Н. Изгиб, кручение и асимптотический анализ пространственной стержневой консоли // Инженерно-строительный журнал. 2014. №5(49). С. 37-43.

15. Кирсанов М.Н. Статический расчет вантовой системы // Известия Московского государственного технического университета МАМИ. 2013. Т. 1. № 3. С. 89-93.

16. Кирсанов М.Н. Дискретная модель свайного фундамента // Инженерно-строительный журнал. 2015. №3(55). C. 3-9.

17. Кирсанов М.Н. Жесткость торсионной подвески микромеханического волнового твердотельного гироскопа // Приборы и системы. Управление, контроль, диагностика. 2015. № 3. С. 18-22.

18. Dong X., Kirsanov M.N. The dependence of the deflection of the truss from the position of the load for an arbitrary number of panels // Вестник научных конференций. 2016. № 1-4 (5). C. 6-7.

19. Jiang H., Kirsanov M. N. An analytical expression for the influence line of the truss // Вестник научных конференций. 2016. № 1-5(5). С.10-11.

20. Kirsanov M.N. Effect of the choice of the instability criterion in creep on the solution of the rod structure optimization problem // Journal of Applied Mechanics and Technical Physics. 1992. Vol. 33. No. 4. P. 573-576. 21. Кирсанов М.Н. Оптимальная высота балочной фермы с учетом линейной ползучести материала // Известия высших учебных заведений. Строительство. 2000. № 5. С. 141.

22. Тиньков Д.В. Оптимальная геометрия плоской балочной раскосной фермы с учетом линейной ползучести материала // Инженерно-строительный журнал. 2016. №1(61). С. 25-32

(C) 2016, Червенко А.Ю.

Прогиб балочной фрермы с треугольной решеткой под действием равномерной нагрузки по нижнему поясу
(C) 2016, Chervenko A.Yu.

The deflection of a girder with a triangular lattice under the action of uniform load on the bottom belt 